\title{
UC addresses needs of California youth
}

C lifornia is home to a $\$ 37$ billion agricultural industry, and some of the best public and private universities in the world - yet we are facing a crisis in the health and education of our young people. The challenges include high childhood obesity, rising school dropout rates, and low student achievement, especially in the sciences.

These challenges are persistent, costing the golden state billions of dollars annually, putting future generations at risk and threatening our long-term viability in the global economy. For example, California's economic costs of overweight, obesity and physical inactivity are the highest in the nation at more than $\$ 41$ billion per year, according to a 2009 study by the nonprofit California Center for Public Health Advocacy.

More than one-third of California school children are overweight or obese, increasing their risk of serious chronic conditions, such as type-2 diabetes and heart disease (according to the Centers for Disease Control). This problem is even more pronounced among the poorest children and ethnic minorities.

We also are grappling with a severe deficit in science literacy, with our students routinely scoring below their peers

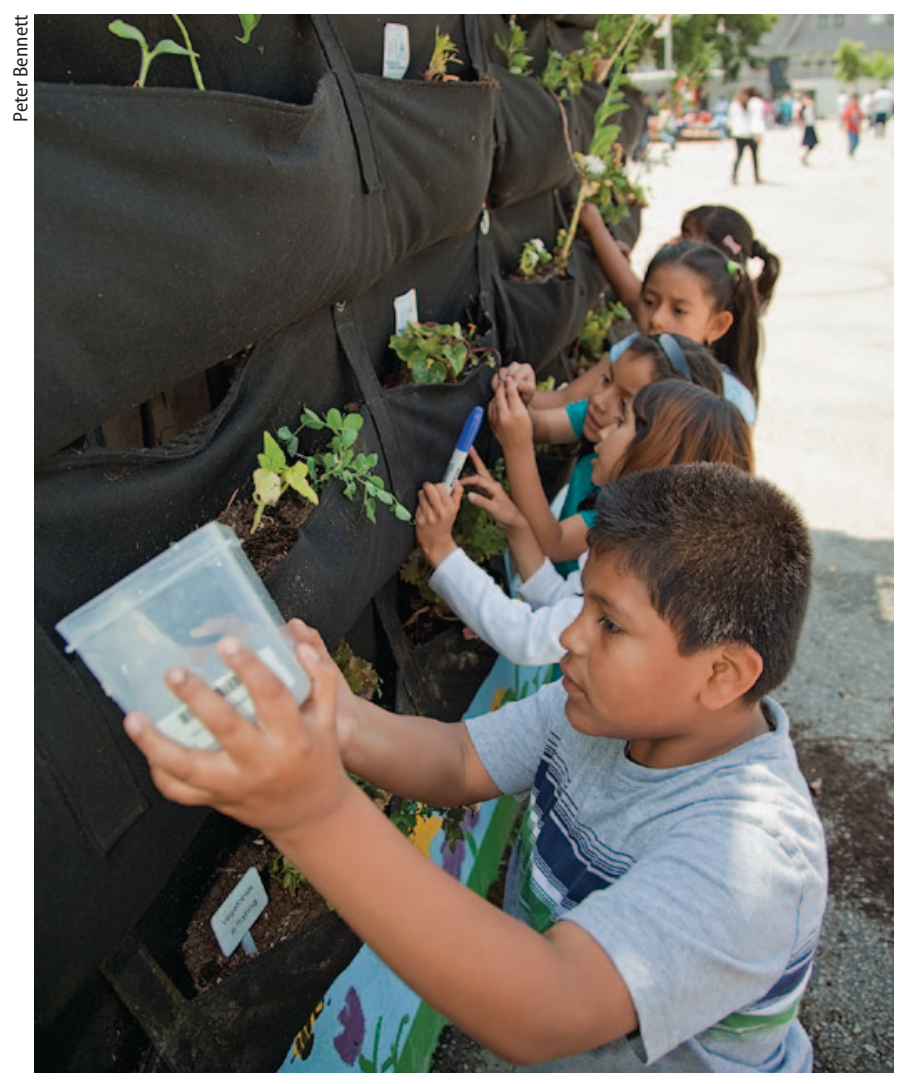

Students water plants in the vertical garden at the Downtown Value School, a charter school in downtown Los Angeles. These pockets are produced by Woolly Pocket Corporation in Los Angeles, and are one part of their school garden program. internationally. Nationwide, our state ranked 47 th in science on the 2011 National Assessment of Educational Progress. This bodes ill, not just for those aspiring to science careers, but for all students in today's knowledge-centered society.

The crisis is compounded as we see that youngsters from highincome families outperform those

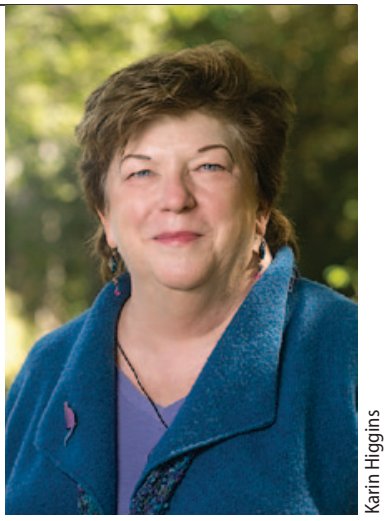

Delaine Eastin

California Superintendent of Public Instruction 1995 to 2003 from low-income, even as poverty in California is rising at one of the fastest rates in our nation. Recent U.S. Census Bureau figures indicate nearly one in four California children now live in poverty. And we see white children outperforming African American and Latino children, as well as boys outperforming girls.

Yet as the most populous and diverse state in the union, with bountiful agriculture and a first-rank higher education system, California can bring unique resources to bear upon these problems. UC Agriculture and Natural Resources (ANR) has embarked upon a 5-year program to promote healthy lifestyles, science literacy and positive youth development in an intertwined effort. The Healthy Families and Communities Strategic Initiative addresses all three goals, through projects that integrate research within communities and schools, with the goal of obtaining science-based information about what works best for children.

For instance, research tells us that hunger is related to both low academic achievement and obesity. We also know that given better food choices such as fresh fruit, children will dramatically increase healthy choices (see page 21). By helping schools to offer more nutritious meals - with more fresh fruits and vegetables - while addressing other dietary changes and increasing physical activity, research under this initiative seeks to improve children's health status (see page 13). In the Shaping Healthy Choices Program (see page 30), researchers launch a comprehensive, controlled community study that includes instructional gardens linked with science and nutrition education, improved diet and exercise. As part of their effort, they will help develop school infrastructure to sustain the program beyond the 5-year funding period.

ANR's strategic effort could not come at a more critical time. The questions before us are:

- Can a multifaceted, integrated school and community program, which targets culturally diverse children, promote healthy diets and physical activity?

- Can it promote science literacy, including nutrition understanding, in formal and informal settings?

- Can we use such programs to promote regional, sustainable agriculture? 


\section{Editorial overview}

- Can we strategically deploy researchers, extension advisors and teachers to carry out these programs?

To improve science performance, ANR proposes we build the capacity of formal educators and $4-\mathrm{H}$ volunteers to engage students with inquiry-based discovery and hands-on learning (see page 47 and page 54). Toward this end the UC 4-H Youth Development Program leaders are already recognized for innovative out-of-school models, curricula and professional development. They will analyze the impacts of youth participation in community-based, out-of-classroom programs that build science knowledge and skill; at the same time, they will measure the impact of professional development on educators.

Grounded in positive youth development rather than deficitbased models (see page 38), UCCE 4-H Youth Development is among the high-quality youth programs that are strongly associated with improved school achievement and graduation rates. The extraordinarily high rate of dropouts in California is of grave concern to all who know that education is becoming more, not less, important. Although the official high school dropout rate in California has been between $12 \%$ and $24 \%$ for several years (based on school reports), we know in fact that $32 \%$ of entering high school freshmen fail to graduate in 4 years. Each year, about 100,000 California youth reach graduation age but do not graduate.

At the end of the day, the Healthy Families and Communities Strategic Initiative is about change, scientifically measurable change, yielding concrete evidence of youth improvement due to these efforts. The initiative will draw on existing data and new findings generated by their interventions, on a wide range of indicators, including science test scores for academic improvement, rates of high school graduation, college enrollment and youth employment. This effort will provide a yardstick to measure healthful school and community environments even as we examine equity in outcomes for different racial, ethnic and gender groups.

Once we have this data, we can make the case for public support, and channel resources in the right direction. Educators

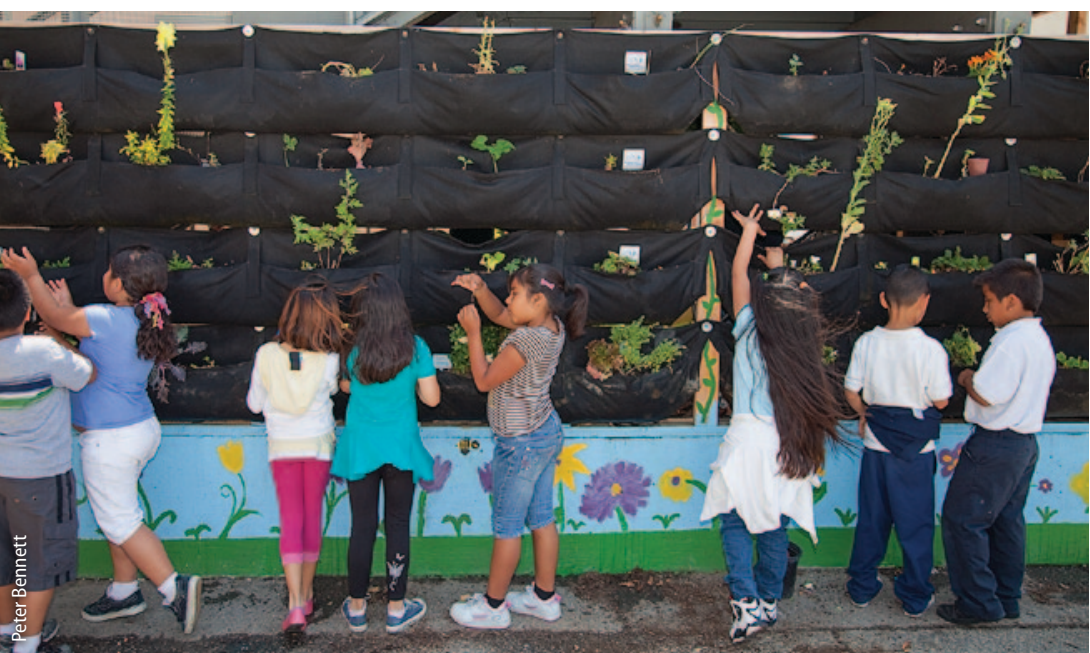

Children tend the planted pockets at the Downtown Value School. Such vertical gardens offer schools, which may have limited space or resources, a cost-effective, easily sustainable option for an instructional garden.

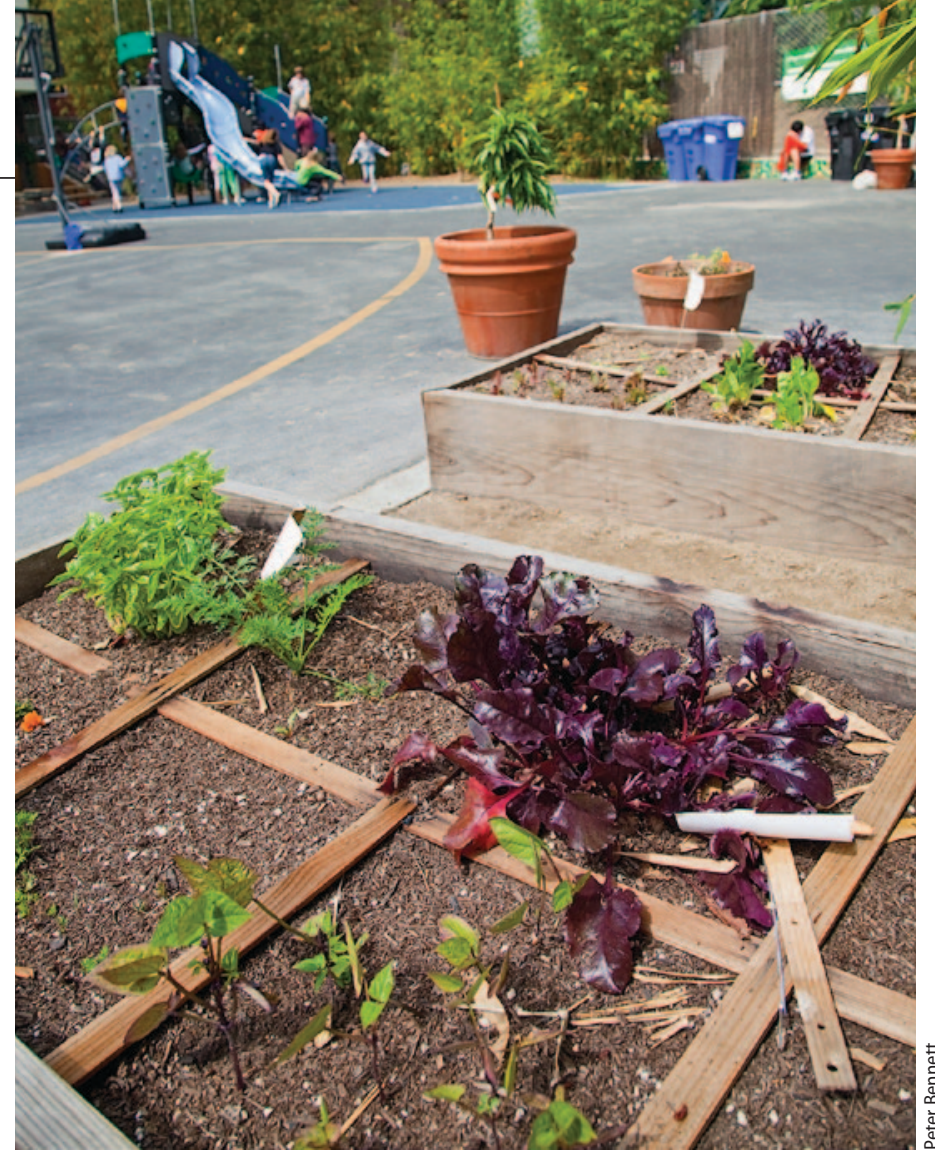

At the Wonderland Elementary School in Laurel Canyon, Los Angeles, vegetables grow in boxed raised beds. As California Superintendent, Eastin initiated a statewide program to establish a garden in every school.

will evaluate data and identify effective programs, observing impacts on public funding support. We need to make citizens aware of the research that supports efforts to advance health and education among children in their communities.

Healthy families and children are vital to our nation and its prosperous future. It is time that key players in higher education join in a project to promote the general welfare by focusing on measurable, scientific initiatives we can pursue to ensure the blessings of liberty to our posterity. I salute UC ANR for this Healthy Families and Communities Strategic Initiative. I thank you on behalf of our future generations.

In 1995, California Superintendent of Public Instruction Delaine Eastin launched an initiative to establish school gardens in every school, the first of its kind in the United States. The California Department of Education (CDE) provided curriculum guides on how to teach standards in the garden program. She oversaw the establishment of gardens in more than 3,000 schools, funded by local districts, parents and private gifts. Eastin also enrolled California as the first state to join the USDA's Team Nutrition program to promote healthier lunches under President Clinton. She advocated education about healthy cooking, seed saving and sowing, family farming and sustainable agricultural practices.

Eastin oversaw the creation of teacher guides to demonstrate how "hands-on" learning about the standards could be achieved in gardens and in cooking classes, which she dubbed "living laboratories." 